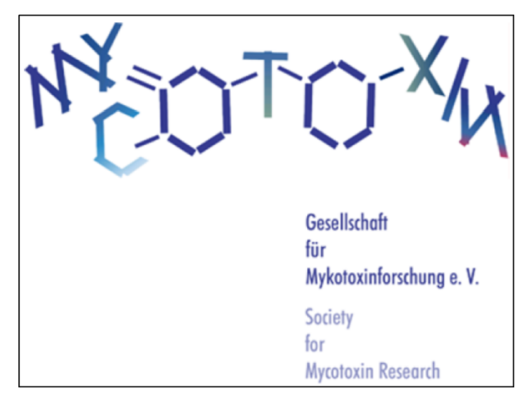

\title{
Brigitte Gedek Award 2014 for Mycotoxin Research
}

Published online: 6 March 2014

(C) Society for Mycotoxin Research and Springer-Verlag Berlin Heidelberg 2014

The Society for Mycotoxin Research is pleased to announce this science award sponsored by Professor Dr. rer. nat. Brigitte Gedek, Ismaning, Germany. The award is endowed with

\section{$€ 10,000$}

with the intention to promote scientific research in mycotoxinology. The award will be granted for the seventh time during the 36th Mycotoxin Workshop (June 16th-18th, 2014, Goettingen, Germany, by the Society for Mycotoxin Research) (http://www.mycotoxin.de).

The award will be given to a scientist or a group of scientists for creative and outstanding achievement in the field of mycotoxin research. Eligible for consideration are individual scientific contributions (master thesis, doctoral thesis, or equivalent) as well as publications in international scientific journals. Routine work in education and scientific management, as well as cumulative research work, will not be considered. Publications which have already received an award, or research work done in the fields of veterinary and medical mycology, are also not eligible for this award.

The award winner is selected by the Science Award Committee. Applications must be submitted via a member of the Society for Mycotoxin Research by mail to the first President of the Society (Prof. Dr. Habil. Manfred Gareis, Chair of Food Safety, Veterinary Faculty, Ludwig-Maximilians-University
Munich, Schoenleutnerstr. 8, 85764 Oberschleißheim, Germany) not later than

April 15th, 2014.

The necessary documents for application (one original and two copies each) are: (1) a Curriculum Vitae of the candidate, (2) the scientific research publication submitted for consideration, and (3) a letter describing the scientific merit of this research work, signed by the member of the Society who submits the application. Details concerning the application procedure are available at www.mycotoxin.de.

The Brigitte Gedek Award has been given on a biennial basis since 2000 and is the most prestigious award in mycotoxin research. Previous laureates are:

2000 Michael Gekle (Wuerzburg, Germany)

2002 Eckhardt Johanning (New York, USA) and Uwe Lauber (Stuttgart, Germany)

2004 Kristian Fog Nielsen (Lyngby, Denmark) and Karsten Meyer (Weihenstephan, Germany)

2006 Franz Berthiller (Tulln, Austria)

2008 Wageha Awad (Vienna, Austria) and Markus Schmidt-Heydt (Karlsruhe, Germany)

2010 Tobias Polte (Leipzig, Germany) 